\title{
A comparison of male attendees and nonattendees at a familial cancer clinic
}

\author{
Elizabeth A. Lobb, MAppSci, PhD ${ }^{1,2,3}$, Clara Gaff, BSc, PhD ${ }^{4,5}$, Bettina Meiser, BA, PhD ${ }^{6,7}$, \\ Phyllis Butow, MPH, PhD ${ }^{8}$, Rebecca Osseiran-Moisson, BA ${ }^{2}$, \\ and Nina Hallowell, $M A, P h D^{9}$; $k$ ConFab Investigators
}

\begin{abstract}
Purpose: This retrospective descriptive Australian study aimed to determine predictors of nonattendance at a familial cancer clinic by men from high-risk breast/ovarian cancer families. Methods: Two hundred twenty-six men from families with a known $B R C A 1$ or $B R C A 2$ mutation were recruited through an epidemiological database of high-risk breast cancer families and completed a self-administered questionnaire. Results: Multivariate analyses using binary logistic regression showed that nonattendance at a familial cancer clinic by men from high-risk breast/ovarian cancer families was associated with younger age (51 vs. 55 years) (odds ratio $=1.03, P=0.04$ ) and lower cancer burden (one relative diagnosed versus two relatives diagnosed) (odds ratio $=2.6$, $P=0.04)$. Conclusion: Compared with men who attended a familial cancer clinic, nonattendees were younger and had fewer relatives diagnosed with breast/ovarian cancer. Unlike previous findings, cancer-specific worry, in particular avoidance was not associated with nonattendance. The number, age, and sex of biological children were not associated with attendance or nonattendance. Hence, some of the assumptions about what makes information on $B R C A 1$ or $B R C A 2$ status salient to men and may therefore influence their attendance at a cancer genetic clinic are not borne out in this study. Genet Med 2009:11(11):806-811.
\end{abstract}

Key Words: BRCA1, BRCA2, men, familial cancer clinics

E xtensive data from surveys conducted in Canada, ${ }^{1}$ the Netherlands, ${ }^{2,3}$ the United Kingdom, $, 4,5$ and France ${ }^{6,7}$ detail the characteristics of women who attend familial cancer clinics (FCCs) and who decide to have genetic testing. Self-reported reasons cited by many women in different countries for attending FCCs include desire to know personal and family risk, awareness of family history, need for reassurance, desire for genetic testing, and to find out about breast cancer screening or prevention. ${ }^{5,6,8,9} \mathrm{~A}$ strong motivating factor seems to be concern

From the ${ }^{1}$ Calvary Health Care Sydney, Kogarah, New South Wales, Australia; ${ }^{2}$ WA Centre for Cancer and Palliative Care, Curtin University of Technology, Bentley, Western Australia, Australia; ${ }^{3}$ School of Nursing, Midwifery and Post-graduate Medicine, Edith Cowan University, Perth, Western Australia, Australia; ${ }^{4}$ Genetic Health Services Victoria, Parkville, Victoria, Australia; ${ }^{5}$ Murdoch Childrens Research Institute, Parkville, Victoria, Australia; ${ }^{6}$ Psychosocial Research Group, Prince of Wales Hospital, Sydney, New South Wales, Australia; ${ }^{7}$ Prince of Wales Clinical School, University of New South Wales, New South Wales, Australia; ${ }^{8}$ Centre for Medical Psychology and Evidence-Based Decision-Making, University of Sydney, New South Wales, Australia; and ${ }^{9}$ Centre for Population Health Sciences, University of Edinburgh, Edinburgh, Scotland.

Elizabeth A. Lobb, MAppSci, PhD, Department of Palliative Care, Calvary Health Care Sydney, Kogarah, New South Wales 2117, Australia. E-mail: Liz.Lobb@sesiahs.health.nsw.gov.au.

Disclosure: The authors declare no conflict of interest.

Submitted for publication April 22, 2009.

Accepted for publication July 14, 2009.

Published online ahead of print September 10, 2009.

DOI: $10.1097 /$ GIM.0b013e3181b780d2 about personal risk triggered by the diagnosis of (or death from) breast cancer in a first-degree relative. ${ }^{4,10} \mathrm{~A}$ recent review indicates that women who attended and choose to have genetic testing were more likely to be affected with cancer, have higher levels of cancer anxiety and perceived risk, and larger numbers of relatives diagnosed with cancer. ${ }^{11}$

Less data are available on men's motivations for attending genetic counseling. Fewer men than women are referred and accept genetic counseling. ${ }^{9,12}$ Men who do take up genetic counseling have a tendency to miss appointments, drop out of testing protocols, ${ }^{13}$ and experience difficulties in establishing appropriate post-test care. ${ }^{14}$ Hallowell et al. ${ }^{15}$ reported that men's decisions to have genetic testing were motivated by a desire to obtain information for their kin and a sense of obligation to determine the carrier status of their children. Their decision to undergo testing was also influenced by family members such as partners and adult children. ${ }^{15}$ Studies also report that men from families with hereditary breast/ovarian cancer fear that they will develop breast cancer, are aware that they are at increased risk of prostate and bowel cancer, and have intrusive thoughts about this increased risk. ${ }^{14,16,17}$ It has also been reported that men admit to preferring avoidance and denial to cope with their cancer risk, ${ }^{16,18}$ avoid discussing their emotions, ${ }^{16,17}$ have unresolved grief about past and future losses, and experience guilt about passing on a potentially lethal gene mutation to their future offspring. ${ }^{17,19,20}$

Very little is known about men who do not attend FCCs because of difficulties in ascertaining these individuals and/or a lack of interest in participating in research studies. Indeed, we are not aware of any published research on the characteristics of men from hereditary breast/ovarian cancer or from families with other hereditary cancer syndromes who opt not to attend FCCs.

Moreover, almost all previous studies have focused on men who attended FCCs who may, or may not, be representative of the larger population of at-risk men. They may represent a socially advantaged and psychologically resourceful group. Alternatively, they may be more distressed than those who do not attend. Thus, it is important to ascertain the attitudes toward management options of men who have not attended specialist clinics. This study aimed to fill these gaps in the literature by recruiting men from high-risk breast cancer families through a population-based epidemiological study and comparing attendees at FCCs with nonattendees.

\section{Hypotheses}

On the basis of the literature exploring attendance in women, it was hypothesized: (i) that nonattendance at FCCs would be influenced by demographic variables, such as marital status, lower education, and nonprofessional employment; (ii) that nonattendance would be significantly associated with lower levels of cancer-related anxiety and lower levels of cancer burden (i.e., the number of male and female family members who have been diagnosed with, or who have died of, cancer); 
(iii) that nonattendance would be associated with having fewer biological children or young children.

\section{MATERIALS AND METHODS}

Men from families with a known $B R C A 1$ or $B R C A 2$ mutation who were 18 to 80 years, not suffering from a mental illness, and could read English proficiently were invited to join the study. Only men at $50 \%$ a priori risk of having inherited a breast cancer gene mutation, that is men whose closest affected relative was a first-degree relative, were included. Men who had a diagnosis of cancer other than nonmelanocytic cancer were excluded.

Participants were recruited through the Kathleen Cuningham Consortium into Familial Breast Cancer (kConFab), a research database of high-risk breast cancer families. $\mathrm{kConFab}$ is an Australian study established to co-ordinate the collection of genetic, epidemiological, and clinical data in Australian families with a dominantly inherited susceptibility to breast cancer. ${ }^{21}$ All family members, i.e., those who carry the family mutation and those who do not, who are registered and consented to the $\mathrm{kConFab}$ study are sent a letter when a mutation has been detected in the family, inviting them to attend a FCC for genetic counseling, and if they wish genetic testing.

Apart from a study-specific newsletter that is mailed to all study participants once a year, participants are not provided with any educational materials. This newsletter includes information about breast cancer genes, FCCs, surveillance, genetic testing, surgical options, personal risk as well as information specifically intended for a male audience, such as the possibility of paternal inheritance of breast cancer gene mutations and the increased risk of prostate cancers in $B R C A 1 / 2$ carriers.

All kConFab participants who were eligible for this study were sent a letter inviting them to participate. An opt-out card was included with a reply paid envelope for those who did not wish to participate or be contacted regarding this study. If the opt-out card was not received within 2 weeks, a self-report questionnaire was mailed with an information sheet and consent form with a stamped addressed envelope for return. If the questionnaire was not returned within 2 weeks, a reminder letter and a second questionnaire were mailed. Ethics approval was obtained from 17 institutional human research ethics committees.

\section{Data collection and measures}

A self-reported questionnaire was completed. The questionnaire included both previously validated and new purposively designed items. All questionnaires were given a code and only this code appeared on the database. To protect the confidentiality and anonymity of study participants, the list of names and addresses of participants was kept in a locked filing cabinet, separate to the coding list. Any computers used for analysis were password protected. Research data will be stored on a computer and paper documents filed for the required time. After this time, all irrelevant material will be disposed of by shredding and erasure of computer-generated data. Only the chief investigators had access to the data.

\section{Predictor variables}

\section{Demographic characteristics}

Age, educational level, marital status, employment status, occupation, number and sex of biological children, and number of relatives who have been diagnosed with, or died from, breast/ovarian cancer were assessed.

\section{Information preference style}

This scale assesses information preference style and is based on a measure adapted from the Cassileth Information Styles Questionnaire.22 Participants are asked to indicate whether they (i) only want information needed to deal with the immediate issues related to their own chance of developing cancer or their family's chance of developing cancer; (ii) additional information only if it is good news; or (iii) as much information as possible, good or bad.

\section{Decision-making preference style}

This item assesses participants' preferences for participation in treatment decisions. ${ }^{23}$ Participants are asked to indicate whether they prefer (i) a passive role in decision making (e.g., "I would like the genetics cancer specialist to make the decision" [about genetic testing or screening]) using all that is known about breast cancer genetics; or (ii) a transitional role between passive and collaborative (e.g., I would like the genetics cancer specialist to make the decisions after considering my needs and opinions); (iii) a collaborative role (e.g., I would like the genetics cancer specialist and I to make the decisions together) or (iv) an active role (e.g., I would like to make the decision using all I know or have learnt about breast cancer genetics or I would like to make the decision, after considering the specialist's opinion). Although the decision-making styles were conceptualized as being on a continuum, for analysis purposes the preference styles were collapsed into passive, collaborative or individual.

\section{Breast cancer genetics knowledge}

An 11-item true-false measure assessed knowledge about breast cancer genetics. The scale is a revised version of a measure previously used in a study on the psychological impact of BRCA1 testing. ${ }^{24}$ In this study, the scale had high internal consistency with a Cronbach's coefficient alpha of 0.79 .

\section{Cancer burden}

Three items assessed the number of family members diagnosed with breast/ovarian cancer, their year of diagnosis (or death if applicable), and their age at the time of diagnosis or death. $^{25-27}$

\section{Cancer-specific worry}

This was measured using the Impact of Events Scale, a 15 -item validated scale measuring intrusion and avoidance thoughts in relation to a specific stressor. ${ }^{28}$ In this study, the particular stressor was concern about the family history of breast/ovarian cancer and the intrusion and the avoidance subscales were highly consistent with Cronbach's coefficient alpha of 0.90 and 0.89 . Scores above 20 on either scale indicate a significant stress response. ${ }^{29}$

\section{Statistical analysis}

Tests of association among demographics (age, educational level, marital status, occupation, and number and sex of biological children), levels of cancer-specific worry (intrusive thoughts and avoidance), decisional and informational preferences, and cancer genetics knowledge were carried out using $\chi^{2}$ tests and Fisher exact tests for categorical variables, $t$ tests and analysis of variance for normally distributed continuous variables and Mann-Whitney and Kruskal-Wallis tests for ordinal or non-normally distributed continuous variables. All variables with a bivariate association with $P<0.25$ were then entered into a linear regression model and progressively eliminated until 
Table 1 Demographics

\begin{tabular}{|c|c|c|c|}
\hline Variables & $\begin{array}{l}\text { Nonattenders } \\
(n=126)\end{array}$ & $\begin{array}{l}\text { Attenders } \\
(n=100)\end{array}$ & $\begin{array}{l}\text { Nonresponders } \\
\quad(n=253)\end{array}$ \\
\hline Age & $\begin{array}{l}\text { Mean } 52 \text { yrs }(\mathrm{SD}=14.6 \\
\quad \text { range }=25-86 \mathrm{yrs})\end{array}$ & $\begin{array}{l}\text { Mean } 55 \text { yrs }(S D=12.4 \\
\text { range }=27-83 \text { yrs })\end{array}$ & $\begin{array}{c}\text { Mean } 49 \text { yrs }(\mathrm{SD}=15.8, \\
\text { range }=19-89 \mathrm{yrs})\end{array}$ \\
\hline \multicolumn{4}{|l|}{ Marital status (\%) } \\
\hline Married/partnered & 75 & 84 & 58 \\
\hline Not married/partnered & 25 & 16 & 41 \\
\hline \multicolumn{4}{|l|}{ Children (\%) } \\
\hline Yes & 88 & 88 & No data available \\
\hline No & 12 & 12 & \\
\hline \multicolumn{4}{|l|}{ Sex } \\
\hline Female & 72 & 73 & \\
\hline Male & 62 & 67 & \\
\hline \multicolumn{4}{|l|}{ Age (yr) } \\
\hline Mean age first child & 26 (SD 15.0) & 29 (SD 13.7) & \\
\hline Mean age second child & 25 (SD 14.3) & 27 (SD 14.0) & \\
\hline Mean age third child & 24 (SD 15.1) & 26 (SD 14.8) & \\
\hline Mean age fourth child & 30 (SD 14.9) & 30 (SD 14.7) & \\
\hline \multicolumn{4}{|l|}{ Education (\%) } \\
\hline Below Year 12 & 47 & 42 & 58 \\
\hline Year 12 and higher & 53 & 58 & 40 \\
\hline \multicolumn{4}{|l|}{ Employment (\%) } \\
\hline Professional & 58 & 42 & No data available \\
\hline Nonprofessional & 42 & 58 & \\
\hline \multicolumn{4}{|l|}{ Mutation status (\%) } \\
\hline Mutation + ve & 39 & 46 & 41 \\
\hline Mutation -ve & 61 & 54 & $57^{a}$ \\
\hline
\end{tabular}

${ }^{a}$ Does not add up to $100 \%$ because of uninformative mutation test results.

the only remaining variables were those with $P<0.05$, or those which confounded the association of interest. ${ }^{30}$

\section{RESULTS}

Four hundred seventy-nine men from families with a known $B R C A 1$ or BRCA2 mutation were approached through the kConFab National Research Database in December 2005. Two hundred twenty-six questionnaires were returned $(47 \%$ response rate), and of these, 100 men (44\%) had previously attended a FCC (attendees) and 126 men (56\%) had not attended (nonattendees).

Two hundred fifty-three men either did not respond to the invitation to participate or choose to opt-out of the study (nonresponders). Table 1 shows the sociodemographic characteristics of the respondents and nonrespondents. Nonresponders were significantly more likely to be younger $\left(\chi^{2}=12.7, P<\right.$ $0.001,49$ vs. 54 years $)$ and less likely to be married $\left(\chi^{2}=15.6\right.$, $P<0.001,58 \%$ vs. $76 \%$ ). There were no significant differences between nonresponders and responders in terms of mutation status or number of first- and second-degree relatives with a $B R C A 1$ or BRCA2 mutation identified.

Almost half of the attendees (49\%) reported that they had genetic testing. Fifty-four percent of attendees were mutation negative and $46 \%$ were mutation positive. We asked the men who had not attended a FCC if they were interested in having genetic testing. Fifty-two percent of men said "definitely yes," $29 \%$ said "probably yes," $10 \%$ "probably not," and 1\% "definitely not" and 9\% were "uncertain."

\section{Decision-making preferences}

Around half of the men preferred a collaborative decisionmaking style (50\% nonattendees vs. $43 \%$ attendees). Nineteen percent of nonattendees preferred the genetics specialist to make medical decisions on issues such as genetic testing or screening compared with $6 \%$ of men who had attended. Approximately $31 \%$ (one third) of nonattendees wanted to make decisions themselves after a specialist opinion, when compared with $29 \%$ of attendees. 


\begin{tabular}{lcc}
\hline \multicolumn{3}{l}{ Table 2 Cancer-specific worry and cancer burden } \\
\hline & $\begin{array}{c}\text { Nonattenders } \\
(n=126)\end{array}$ & $\begin{array}{c}\text { Attenders } \\
(n=100)\end{array}$ \\
\hline $\begin{array}{l}\text { Cancer-specific worry } \\
\text { Intrusion Scale }\end{array}$ & $8(4.5,2-27)$ & $9(4.4,6-27)$ \\
Avoidance Scale & $9(5.05,2-28)$ & $11(5.2,8-29)$ \\
Total Intrusion and & $17(9.45,2-55)$ & $21(9.2,15-53)$ \\
$\quad$ Avoidance Scale & & \\
Cancer burden & $1(1.07,1-8)$ & $2(0.96,1-5)$ \\
Relatives diagnosed & $2(1.32,1-7)$ & $2(1.54,1-8)$ \\
Relatives died & \\
\hline Values are given as median (SD, range).
\end{tabular}

\section{Information preferences}

Just more than half of the men (58\%) who had not attended a FCC reported that they preferred to receive all information relating to their own chance of developing cancer or their family's chance of developing cancer, regardless of whether it was good or bad, compared with $70 \%$ of men who had attended. Less than half of the men wanted information to deal with immediate issues only ( $41 \%$ of nonattendees vs. $30 \%$ of attendees).

\section{Cancer burden}

Men who had not attended a FCC reported having one family member who had been diagnosed with breast/ovarian cancer and were still alive $(\mathrm{SD}=1.2$, range $=1-8)$ compared with a median of two family members $(\mathrm{SD}=0.94$, range $=1-5$ ) reported by men who had attended (Table 2 ).

\section{Cancer-specific worry}

The majority of men did not show significant levels of cancer-specific worry with fewer than 10 men in either group scoring more than 20 on both intrusion and avoidance scales (Table 2).

\section{Breast cancer genetics knowledge}

Men who had never attended a FCC scored a median of 7 correct answers on the 11 breast cancer genetics knowledge scale $(\mathrm{SD}=2.87$, range $=0-11)$ compared with a median of 8 correct answers $(\mathrm{SD}=2.34$, range $=0-11)$ for men who had attended. Areas where fewer nonattendees gave correct answers concerned the role of male inheritance with $58 \%$ of men unaware that they have an increased risk of developing other cancers; $51 \%$ were unaware that their sons could inherit a faulty gene; and the majority (92\%) were unaware that not every person with a strong family history can be offered genetic testing (Table 3).

\section{Predictors of nonattendance at familial cancer clinics}

Bivariate analyses showed men's decision-making styles, cancer-specific worry (avoidance), total cancer-specific worry (intrusion and avoidance), and knowledge were significantly associated with nonattendance at the FCC (Table 4).

Multivariate analyses using binary logistic regression showed that nonattendance at a FCC was associated with younger age ( 51 vs. 55 years) (odds ratio $=1.03, P=0.04$ ) and lower cancer burden (one relative diagnosed vs. two relatives) (odds ratio $=2.6, P=0.04$ ).
Table 3 Breast cancer genetics knowledge

\begin{tabular}{|c|c|c|}
\hline True/false statement & $\begin{array}{l}\text { Nonattenders } \\
(\% \text { correct })\end{array}$ & $\begin{array}{l}\text { Attenders } \\
(\% \text { correct })\end{array}$ \\
\hline Breast cancer is always inherited & 64 & 68 \\
\hline $\begin{array}{l}\text { Men can carry a faulty breast/ovarian } \\
\text { cancer gene }\end{array}$ & 74 & 91 \\
\hline $\begin{array}{l}\text { All men who have a faulty breast/ } \\
\text { ovarian cancer gene will get breast } \\
\text { cancer }\end{array}$ & 73 & 81 \\
\hline $\begin{array}{l}\text { Men who have a faulty } \\
\text { breast/ovarian cancer gene can be } \\
\text { at risk of other cancers }\end{array}$ & 42 & 60 \\
\hline $\begin{array}{l}\text { Daughters of men who have a faulty } \\
\text { breast/ovarian cancer gene can } \\
\text { inherit that faulty gene from their } \\
\text { fathers }\end{array}$ & 60 & 86 \\
\hline $\begin{array}{l}\text { Sons of men who have a faulty } \\
\text { breast/ovarian cancer gene can } \\
\text { inherit that faulty gene from their } \\
\text { father }\end{array}$ & 49 & 70 \\
\hline $\begin{array}{l}\text { A man who does not have a faulty } \\
\text { breast cancer gene can still get } \\
\text { breast cancer }\end{array}$ & 61 & 73 \\
\hline $\begin{array}{l}\text { In a family where a faulty breast } \\
\text { cancer gene has been found, all } \\
\text { members of the family will have } \\
\text { the faulty gene }\end{array}$ & 77 & 86 \\
\hline $\begin{array}{l}\text { There is more than one } \\
\text { breast/ovarian cancer gene }\end{array}$ & 38 & 59 \\
\hline $\begin{array}{l}\text { In a family where a faulty breast } \\
\text { cancer/ovarian cancer gene has } \\
\text { been found, those without the } \\
\text { faulty gene have the same risk of } \\
\text { getting cancer as people in the } \\
\text { general population }\end{array}$ & 56 & 63 \\
\hline $\begin{array}{l}\text { Not every person with a strong } \\
\text { family history of breast cancer can } \\
\text { be offered a genetic test }\end{array}$ & 8 & 10 \\
\hline
\end{tabular}

\section{DISCUSSION}

To our knowledge, no previously reported study has effectively dealt with the potential ascertainment bias associated with recruiting men through specialist clinics. This study addressed this issue by identifying predictors of nonattendance at a FCC in a population-based sample of high-risk men recruited through an epidemiological study.

We found that younger men and men with fewer relatives who had been diagnosed with breast/ovarian cancer were less likely to have attended a FCC. It is of interest to compare these findings to those from studies that examined the predictors of genetic testing uptake, as there is evidence that people attending FCCs are self-selected for interest in genetic testing. Indeed, such studies show an association between strength of family history and uptake of testing ${ }^{24,31}$; however, findings on the association between age and test uptake are mixed. ${ }^{32,33}$

The uptake of genetic counseling (44\%) and testing (49\%) in our sample is comparable with that reported for women from high-risk breast cancer families recruited through the same 
Table 4 Bivariate associations with non-attendance at the familial cancer clinic

\begin{tabular}{lccc}
\hline & $\begin{array}{c}\text { Nonattenders } \\
(n=126)\end{array}$ & $\begin{array}{c}\text { Attenders } \\
(n=100)\end{array}$ & $P$ \\
\hline $\begin{array}{l}\text { Decision-making style_Dr. only } \\
\begin{array}{l}\text { Information preferences_to deal } \\
\text { with immediate issues only }\end{array}\end{array}$ & $19 \%$ & $9 \%$ & 0.02 \\
Avoidance & Median 9 & Median 11 & 0.04 \\
Intrusion & Median 8 & Median 9 & 0.08 \\
Total avoidance and intrusion & Median 17 & Median 21 & 0.03 \\
Knowledge & Median 7 & Median 8 & $<0.001$ \\
Not married & $25 \%$ & $16 \%$ & 0.14 \\
Age & Median 51 & Mean 55 & 0.10 \\
Total no, relatives diagnosed & Median 1 & Median 2 & 0.08 \\
\hline
\end{tabular}

Australian population-based epidemiological database (kCon$\mathrm{Fab}$ ), where $59 \%$ were reported to have attended a FCC and $49 \%$ to have had genetic testing. ${ }^{34}$

The only difference in terms of decision-making preferences between men who attended and men who did not attend was that more nonattendees preferred the genetics specialist to make medical decisions on issues such as genetic testing or screening (19\%), (vs. 6\% of men who had attended). This could be attributed to attendee's experiences of familial cancer services and the active role they may have been encouraged to play by these services in decision-making around issues such as genetic testing and screening. In addition, almost half of the nonattendees $(41 \%)$ only wanted information to deal with immediate issues. This suggests that avoidance as a coping style may be present in these men; however, our data did not show clinically significant or indeed high levels of cancer-specific worry (avoidance or intrusion). The men in this study had similar low levels of psychological distress as reported for women recruited through the same population-based epidemiological study of high-risk breast cancer families. ${ }^{3}$

We observed a lack of knowledge among nonattendees about some specific issues, including their risk of developing cancers other than breast cancer and the risk that their sons could inherit a faulty breast cancer gene. Given that kConFab newsletter includes articles that are specifically targeted for a male audience, these gaps in knowledge among nonattendees suggest that the newsletter is either not read by all men or that the information needs to be personalized during a visit at a FCC to be understood.

It could be assumed that men with children, particularly daughters might be more motivated to attend for genetic testing; however, this was not borne out by the data. There were no significant differences in the number or age of biological children between attendees and nonattendees with ages of children ranging between 26 and 30 years. Hence, we cannot argue that men did not attend because they had fewer or younger children. Both groups had children within the age groups for whom knowledge of their genetic status and a screening program may be appropriate.

There was no significant difference between men who attended a FCC and men who did not according to their mutation status (mutation positive or mutation negative). This is not surprising given that men do not know their status before testing and men in the study were at a $50 \%$ risk of inheriting a $B R C A 1$ or $B R C A 2$ mutation. More surprisingly, the majority of men who did not attend a FCC were interested in genetic testing (81\%). The data on knowledge, above, suggest that men might not be aware of the relevance of genetic testing for their own health, however, other explanations are possible. For instance, failure to have testing may relate to limited access or awareness of services, which offer genetic testing. Men may be "deferring" testing rather than making a decision not to proceed or their perceived risk may be lower as nonattendees had a significantly lower cancer burden.

The strengths and limitations of our study should be mentioned. This study assessed 226 men, and to our knowledge, this is the largest sample of men from hereditary breast/ovarian families with a known mutation, who were assessed in relation to their psychosocial adjustment. The sample size was sufficient to detect a small to medium effect size (0.4) difference in characteristics between attendees and nonattendees; we consider this difference to be clinically meaningful and an adequate sample size to confirm our hypotheses. The strength of the study is that men were ascertained through a large breast cancer genetics registry, where participants were recruited through a diversity of sources of index case ascertainment and subsequent systematic recruitment, leading to as representative a sample as is realistically possible without a population-based survey.

Furthermore, just more than half of the men in both groups were educated above Year 12 compared with 54\% in the general Australian population. ${ }^{35}$ These sample characteristics suggest that our sample is representative of, and our findings able to be generalized to, the larger population of high-risk men. Conversely, it should be noted that participation in a breast cancer genetics study and access to the study newsletter might have altered attitudes and knowledge levels, and a population-based survey of participants would have been ideal. Finally, the response rate was only $47 \%$, which is lower than the $67 \%$ response rate to questionnaires reported in a study of women drawn from the same population-based study, ${ }^{36}$ and there was some indication of response bias in that nonresponders were more likely to be younger and less likely to be married. Finally, this is a retrospective study, which means that men's recollection of their decision making may be biased by their subsequent experiences.

None of our hypotheses were confirmed with nonattendance being unrelated to demographics (apart from age) or psychological variables. A lower cancer burden was associated with men's nonattendance. Having more affected family members and as Hallowell et al. ${ }^{15,20}$ suggested perhaps persuasion by a family member for men to go for genetic counseling and testing may explain attendance.

In conclusion, some of the assumptions we may have about what makes information on $B R C A 1$ or $B R C A 2$ status salient to men and may therefore influence their attendance at a cancer genetic clinic is not borne out. For example, most studies in men from high-risk breast cancer families show that men attend cancer genetic services because of their concern for their children. However, we have found no difference among the number, age, and sex of biological children and between attendees and nonattendees. In addition, cancer-specific worry (avoidance) was not related to nonattendance. In our earlier study, we found that men go to a cancer genetic service because they are asked to attend by a female family member. ${ }^{37}$ Other studies suggest that social desirability and men's sense of obligation within the family are the major factors determining their attendance at a cancer genetic clinic. ${ }^{15,38}$ 
Being aware of men's sense of obligation ${ }^{38}$ within the family, that their attendance is not contingent on having daughters, and that younger men are less likely to attend a FCC is useful in tailoring information and communication messages that raise the awareness and meet the needs of men from high-risk breast cancer families.

\section{ACKNOWLEDGMENTS}

Associate Prof. Elizabeth Lobb was supported by a National Health and Medical Research Council of Australia, Australian Clinical Research Fellowship \#222915. Associate Prof. Bettina Meiser was supported by a National Health \& Medical Research Council (NHMRC) of Australia Public Health Fellowship \# 007079. Prof. Phyllis Butow was supported by an NHMRC Principal Research Fellowship. Dr. Nina Hallowell is supported by a Leverhulme Trust Study Abroad Fellowship. We wish to thank Heather Thorne, Eveline Niedermayr, all the kConFab research nurses and staff, the heads and staff of the Family Cancer Clinics, and the Clinical Follow Up Study (funded by NHMRC Grants 145684, 288704, and 454508) for their contributions to this resource, and the many families who contribute to $\mathrm{kConFab}$. $\mathrm{kConFab}$ is supported by grants from the National Breast Cancer Foundation, the National Health and Medical Research Council (NHMRC) and by the Queensland Cancer Fund, the Cancer Councils of New South Wales, Victoria, Tasmania and South Australia, and the Cancer Foundation of Western Australia.

\section{REFERENCES}

1. Metcalf KA, Liede A, Hoodfar E, Scorr A, Scott A, Foulkes WD, Narod SA. An evaluation of needs of female BRCA1 and BRCA2 carriers undergoing genetic counselling. J Med Genet 2000;37:866-874

2. Van Asperen CJ, Van Dijk S, Zoeteweij MW, Timmermans DR. What do women really want to know? Motives for attending familial breast cancer clinics [comment]. J Med Genet 2002;39:410-414.

3. Bleiker EM, Aaronson NK, Menko FH. Genetic counseling for hereditary cancer: a pilot study on experiences of patients and family members. Patient Educ Couns 1997;32:107-116.

4. Brain K, Gray J, Norman P, et al. Why do women attend familial breast cancer clinics? J Med Genet 2000;37:197-202.

5. Hallowell N, Murton F, Statham H, Green JM, Richards MP. Women's need for information before attending genetic counselling for familial breast or ovarian cancer: a questionnaire, interview and observational study. BMJ 1997;314:281-282.

6. Julian-Reynier C, Eisinger F, Chabal F, et al. Cancer genetics clinics: target populations and consultees' expectations. Eur J Cancer 1996:32A:398-403.

7. Julian-Reynier C, Eisinger F, Chabal F, et al. Cancer genetic clinics: why do women who already have had cancer attend. Eur J Cancer 1998;34:15491553 .

8. Hopwood P. Psychological issues in cancer genetics: current research and future priorities. Patient Educ Couns 1997;32:19-31.

9. Fraser L, Bramald S, Chapman $\mathrm{C}$, Chu C, et al. What motivates interest in attending a familial cancer genetics clinic. Fam Cancer 2003;2:159-168.

10. Hopwood P, Evans G, Howell A. Women at high risk of breast cancer: risk perception and counselling needs. Cancer Detect Prev 1993;17:Abs 009/002.

11. Butow P, Lobb EA, Meiser B, et al. Psychological outcomes and risk perception after genetic testing and counselling in breast cancer: a systematic review. Med J Aust 2003; 178:77-81.

12. Wonderling D, Hopwood P, Cull A, Douglas F. A descriptive study of UK cancer genetics services: an emerging clinical response to the new genetics. Br J Cancer 2001;85:166-170.

13. Dudok de Wit AC, Meijers-Heijboer EJ, Tibben A, et al. Effect on a Dutch family of predictive DNA-testing for hereditary breast and ovarian cancer. Lancet 1994;344:197.

14. Liede A, Metcalfe K, Hanna D, et al. Evaluation of the needs of male carriers of mutations in BRCA1 or BRCA2 who have undergone genetic counseling. Am J Hum Genet 2000;67:1494-1504.

15. Hallowell N, Ardern-Jones A, Eeles R, et al. Men's decision-making about predictive BRCA1/2 testing: the role of family. J Genet Couns 2005;14:207-217.

16. McAllister MF, Evans DG, Ormiston W, Daly P. Men in breast cancer families: a preliminary qualitative study. J Med Genet 1998;35:739-744.

17. Dudok de Wit AC, Tibben A, Frets PG, et al. Males at-risk for the BRCA1gene, the psychological impact. Psycho Oncology 1996;5:251-257.

18. Daly PA, Nolan C, Green A, et al. Predictive testing for BRCA1 and 2 mutations: a male contribution. Ann Oncol 2003;14:549-553.

19. d'Agincourt-Canning L, Baird P. Genetic testing for hereditary cancers: the impact of gender on interest, uptake and ethical considerations. Clin Rev Oncol Hemato 2006;58:114-123.

20. Hallowell N, Arden-Jones A, Eeles R, et al: Guilt, blame and responsibility: men's understanding of their role in the transmission of BRCA1/2 mutations within their family. Sociol Health Illn 2006;28:969-988.

21. Osborne R, Hopper JL, Kirk J, Chenevix-Trench G. A resource for studies into the genetics, epidemiology, biology, pathology and psychosocial aspects of breast cancer families. Identification and characterisation of eligible families. Med J Aust 2000;172:463-464.

22. Cassileth BR, Zupkis RV, Sutton-Smith K, March V. Information and participation preferences among cancer patients. Ann Intern Med 1980;92:832-836.

23. Degner LF, Sloan J. Decision making during serious illness: what role do patients really want to play? J Clin Epidemiol 1992;45:300-303.

24. Lerman C, Narod S, Schulman K, et al. BRCA1 testing in families with hereditary breast-ovarian cancer. JAMA 1996;275:1885-1892.

25. Watson M, Lloyd SM, Eeles R, et al. Psychosocial impact of testing (by linkage) for the BRCA1 breast cancer gene: an investigation of two families in the research setting. Psycho Oncology 1996;5:233-239.

26. Meiser B, Butow P, Barratt A, Suthers G, et al. Attitudes to genetic testing for breast cancer susceptibility in women at increased risk of hereditary breast cancer. J Med Genet 2000;37:472-476.

27. Lobb EA, Butow P, Meiser B, et al. Tailoring communication in consultations with women from high risk breast cancer families. $\mathrm{Br} J$ Cancer 2002;87:502-508.

28. Horowitz M, Wilner N, Alvarez W. Impact of Events Scale: a measure of subjective stress. Psychosom Med 1979:41:209-218.

29. Cella DF, Mahon SM, Donovan M. Cancer recurrence as a traumatic event. Behav Med 1990;16:15-22.

30. Hosmer DW, Lemeshoe S. Applied logistic regression. Brisbane: John Wiley \& Sons, 1989

31. Hadley D, Jenkins J, Dimond E, et al. Genetic counseling and testing in families with hereditary nonpolyposis colorectal cancer. Arch Int Med 2003; 163:573-582.

32. Biesecker BB, Ishibe N, Hadley DW, et al. Psychosocial factors predicting BRCA1/BRCA2 testing decision in members of hereditary breast and ovarian cancer families. Am J Med Genet 2000;93:257-263.

33. Foster C, Evans DG, Eeles R, Eccles D, et al. Non-uptake of predictive genetic testing for BRCA1/2 among relatives of known carriers: attributes, cancer worry, and barriers to testing in a multicenter clinical cohort. Genet Test 2004;8:23-29.

34. Phillips $\mathrm{K}$, Jenkins MA, Lindeman $\mathrm{G}$, et al. Risk-reducing surgery, screening and chemoprevention practices of BRCA1 and BRCA2 mutation carriers: a prospective study. Clin Genet 2006;70:198-206.

35. Australian Bureau of Statistics. ABS Catalogue No. 6278 Education and Training Experience, 2005.

36. Phillips KA, Butow PN, Stewart AE, et al. Predictors of participation in clinical and psycho-social follow-up of the kConFab breast cancer family cohort. Fam Cancer 2005;4:105-113.

37. Lobb EA, Gaff C, Meiser B, Butow P, Osseiran-Moisson R, Hallowell N. Attendance of men at the familial cancer clinic: what they value from the consultation. Genet Med 2009;11:434-440

38. Daly MB. The impact of social roles on the experiences of men in BRCA1/2 families: implications for counseling. J Genet Coun 2009;18:42-48. 